УДК $1(091)$

DOI 10.18413/2712-746X-2020-44-3-427-436

\title{
Гегельянские истоки культурно-исторической теории деятельности
}

\author{
Бланден Э. \\ Марксистский сетевой архив (marxists.org), \\ Мельбурн, Австралия \\ E-mail: andyb@marxists.org
}

Перевод с англ: Майданский АД.

Белгородский государственный национальный исследовательский университет, Россия, 308015, г. Белгород, ул. Победы, 85

E-mail: maidansky@bsu.edu.ru

\begin{abstract}
Аннотация. Показано, что по крайней мере четыре основополагающих понятия культурно-исторической теории деятельности были сформулированы уже Гегелем, а именно: (1) единица анализа как ключевое понятие в аналитико-синтетическом познании, (2) ключевая роль действий, опосредованных артефактами, (3) разграничение цели и мотива в деятельности и (4) дистинкция истинного понятия и псевдопонятия. Подход Выготского - развивающий, а не основанный на неизменных категориях, и этот подход к реальности был инициирован Гегелем. Эти четыре концептуальных идеи не исчерпывают пути, на которых Выготский, Леонтьев и их последователи продолжили работу, начатую Гегелем. Выготский, подобно Гегелю, рассматривает понятия как имплицитно заложенные в констелляциях материальной культуры способы ее использования в обществе, а не как субъективные образования, создаваемые индивидуальным мозгом. Концепция генезиса речи и мышления у Выготского напоминает представление Гегеля о генезисе современного государства.
\end{abstract}

Ключевые слова: единица анализа, действие, артефакт, понятие, псевдопонятие, культура, Гегель, Выготский.

Благодарности: перевод выполнен А.Д. Майданским при финансовой поддержке Российского научного фонда (РНФ) в рамках научного проекта № 20-18-00028.

Для цитирования: Бланден Э. 2020. Гегельянские истоки культурно-исторической теории деятельности. Пер. с англ. Майданский А.Д. NOMOTHETIKА: Философия. Социология. Право. 45 (3): 427-436. DOI 10.18413/2712-746X-2020-44-3-427-436

\section{The hegelian sources of cultural historical activity theory}

\author{
Andy Blunden \\ Marxists Internet Archive Secretary (marxists.org), \\ Melbourne, Australia \\ E-mail: andyb@marxists.org \\ Transl. from English Andrey D. Maidanskii \\ Belgorod National Research University, \\ 85 Pobeda St, Belgorod, 308015, Russia \\ E-mail: maidansky@bsu.edu.ru
}

\begin{abstract}
It will be shown that at least four foundational concepts of Cultural Historical Activity Theory were previously formulated by Hegel, viz., (1) the unit of analysis as a key concept for
\end{abstract}


analytic-synthetic cognition, (2) the centrality of artifact-mediated actions, (3) the definitive distinction between goal and motive in activities, and (4) the distinction between a true concept and a pseudoconcept. These four concepts do not exhaust the ways in which Vygotsky, Leontyev and their followers continued the project begun by Hegel. Vygotsky, like Hegel, sees concepts as implicit in the constellation of material culture and the manner of its use in a community, rather than as subjective formations created by an individual brain. Vygotsky's conception of the genesis of speech and intellect is similar to Hegel's conception of the genesis of the modern state.

Key words: unit of analysis, artifact, action, concept, pseudoconcept, culture, Hegel, Vygotsky.

Acknowledgements: the translation was made by A.D. Maydansky with the financial support of the Russian science Foundation (RPF) in the framework of scientific project No. 20-18-00028.

For citation: Blunden A. 2020. The hegelian sources of cultural historical activity theory. Transl. from English Maidanskii A.D. NOMOTHETIKA: Philosophy. Sociology. Law series. 45 (3): 427-436 (in Russian). DOI 10.18413/2712-746X-2020-44-3-427-436

\section{1. Единица анализа}

В разделе «Идея» в «Науке логики», где Гегель обрисовывает метод аналитического и синтетического познания, он поясняет, что выделение предмета изучения науки должно осуществляться согласно внутренней природе самого этого предмета, а не по произвольной, субъективной схеме, навязанной извне.

Вот ключевой отрывок из «Науки логики»: «Принадлежащее понятию движение от всеобщего к особенному составляет основу и возможность синтетической науки, некоторой системы и систематического познания. Для этого первое требование, как было показано, состоит в том, чтобы вначале предмет рассматривался в форме чего-то всеобщего. Если в действительности (будь это действительность природы или духа) субъективному, естественному познанию дана как первое (das Erste) конкретная единичность, то, напротив, в познании, которое по крайней мере постольку есть постижение, поскольку оно имеет своей основой форму понятия, первым должно быть простое, выделенное из конкретного, так как лишь в этой форме предмет имеет форму соотносящегося с собой всеобщего и сообразного с понятием непосредственного» (здесь и далее курсив - Б.Э.) [Гегель 1970, т. 3, с. 262].

«Первое» - это перевод немецкого der Ersten, первичное или исходное. «Первым» является понятие, с которого должна начинаться каждая наука.

Во-первых, Гегель говорит, что синтетическая фаза науки должна начинаться с «чего-то простого». Это предписание относится к «действительности равным образом природы и духа» (т.е. к естественным и гуманитарным наукам), но явно не к Логике. Среди примеров этого простого нечто - «линия», «овладение» и «цель».

Во-вторых, Гегель описывает это простое Erste как «конкретную единичность, данную субъективному, естественному познанию». Einzel означает «единичный», a Einzelheit означает «единичность» или «индивидуальность». «Естественное познание» относится к здравому смыслу или нормативному восприятию некоего процесса в рамках определенного социального образования, предшествующего любой попытке критического анализа или синтетического познания.

«Наука логики» не может быть структурирована в соответствии с этим методом, потому что логические категории невозможно воспринять как «нечто простое» посредством «естественного познания»; в Логике «метод есть осознание формы внутреннего самодвижения ее содержания» [Гегель 1970, т. 1, с. 107]. Это не относится к естественным и гуманитарным наукам, в которых предмет науки воспринимается как внешнее по отноше- 
нию к субъекту. Erste - продукт аналитического познания: в узловых точках развития науки «простое нечто» абстрагируется от конкретного в опыте и подчиняется синтетическому познанию, то есть диалектической реконструкции целостного процесса. Эти узловые точки размечают моменты чередования аналитического и синтетического познания.

Это «простое нечто» должно быть «абстрагировано от конкретного» посредством анализа. Таким образом, начало любой науки (кроме Логики) требует абстрагирования такого рода индивидуальности из всей конкретной сферы опыта, что может стать отправным пунктом для синтетической реконструкции конкретного в теоретической форме. Этот акт абстракции требует понимания всего процесса в целом.

«Аналитическое познание... начинает с предмета, выступающего в качестве предпосылки, стало быть, с единичного, конкретного предмета, причем все равно, есть ли он уже готовый для представления предмет или же некоторая задача, т.е. дан лишь в своих обстоятельствах и условиях, но сам еще не выделен из них и не представлен в простой самостоятельности» [Гегель 1970, т. 3, с. 247].

Цель этого пассажа становится понятной, когда Гегель говорит, что «первое требование, как было показано, состоит в том, чтобы вначале предмет рассматривался в форме чего-то всеобщего» [Гегель 1970, т. 3, с. 262]. То есть конкретная индивидуальность, являющаяся продуктом анализа, одновременно является всеобщей; иными словами, это архетип или «клеточка» всего организма, которая должна быть синтезирована в теории. Данный процесс представлен в первом томе Логики, состоящем из двух разделов: «Бытие» и «Сущность».

Обратите внимание, что «нечто простое» - это индивидуальность, и в этом разница, например, между «моральностью» и моральными поступками, между «искусством» и произведением искусства. Индивидуальность дискретна, ограничена, а не континуальна или нематериальна; это скорее частица, чем «материя», скорее нечто, чем всеобщее, скорее действие, чем практика. Маркс кратко выразил эту идею в «Замечаниях на книгу Адольфа Вагнера» по поводу «Капитала»: «Я исхожу не из “понятий”, стало быть также не из “понятия стоимости”, и потому не имею никакой нужды в “разделении” последнего. Я исхожу из простейшей общественной формы, в которой продукт труда представляется в современном обществе, это - “товар”» [Маркс 1961, с. 383].

Согласно Гегелю, наука, идущая по пути синтетического познания, должна далее отталкиваться от этой конкретной индивидуальности, которая считается абстрактным (т.е. простым и абстрагированным от конкретных обстоятельств ее существования) моментом Всеобщего, каковое и является предметом науки, продвигаясь отсюда к различным конкретным формам Всеобщего. Так описывается путь науки в Логике: понятие конкретной индивидуальности сначала выставляется (и может появиться необходимость его уточнения на этом этапе), затем подвергается имманентной критике, последовательно выводящей за его пределы через исследование скрытых в нем конкретных форм, до тех пор пока не возникнет противоречие, которое может быть разрешено в действительности только открытием некой новой конкретной индивидуальности.

Следует отметить, что Гегель не верит в то, что естественные и гуманитарные науки могут быть развиты с помощью одной лишь логики, без обращения к наблюдениям и экспериментам. «Рациональное само по себе начало науки переходит в случайное вследствие того, что всеобщее низводится в область эмпирической единичности и действительности. В этом царстве изменчивости и случайности понятие не имеет силы, а могут иметь силу лишь основания» [Гегель, 1974, т. 1, с. 101].

В «Науке логики» простые понятия обозначают начало каждой книги, соответственно: бытие, рефлексия и абстрактное понятие. Эти категории в известном смысле также «простые нечто», и их развитие дает модель синтетической науки, применяемой в 
естественных и гуманитарных науках, но в качестве категорий они не могут быть описаны ни как Einzelnen, ни как «абстрагированное от конкретного» целое.

В дальнейшем в «Энциклопедии философских наук» демонстрируется использование «простых нечто», имеющих форму отношения всеобщего к самому себе. В частности:

- первая книга «Философии природы» по видимости начинается с «пространства», но ее непосредственное начало образуют гораздо более определенные понятия: точка, линия и плоскость (или поверхность, которая может охватывать пространство);

- вторая книга «Философии природы» по видимости начинается с «Физики», а на самом деле - с частицы;

- «Органическая физика» по видимости - о «жизни», в действительности же она начинается с организма;

- три книги «Философии субъективного духа»: «Душа», начинающая с чувств, «Сознание», начинающая с ощущений, и книга о «Духе»;

- в «Философии объективного духа» абстрактное право, или частная собственность, проходит через следующие ступени: собственность = владение, пользование и отчуждение имущества; договор = дарение, обмен и залог; и «право против нарушенного права»= непредумышленное нарушение и преступление; га, добра;

- «Моральность» раскрывается через понятия умысла, средства, намерения, бла-

- «Нравственность» - через понятия семьи, рынка (системы потребностей и труда), государственной власти, корпораций, государства и других институтов;

- в «Философии Абсолютного духа» раздел «Искусство» по видимости - о «форме красоты» (die Gestalt der Schönheit), начинается же он с понятия произведения искусства; «Религия Откровения» начинается с «конкретной индивидуальности» (konkrete Einzelheit), а «Философия» - с умозаключения.

Как видно из приведенного выше списка, каждая из наук, рассмотренных Гегелем в «Энциклопедии», имеет своим предметом общий феномен, объединяемый синтетическим познанием; последнее начинает с дискретной простой сущности или действия, которое, будучи единичным, является в то же время всеобщим.

\section{Выготский о единице анализа}

Выготский назвал такое всеобщее «единицей анализа». В первой главе «Мышления и речи» он пишет: «Само слово, представляющее собой живое единство звука и значения и содержащее в себе, как живая клеточка, в самом простом виде основные свойства, присущие речевому мышлению в целом...». И поясняет, что это - «анализ, расчленяющий сложное единое целое на единицы. Под единицей мы подразумеваем такой продукт анализа, который в отличие от элементов обладает всеми основными свойствами, присущими целому, и который является далее неразложимыми живыми частями этого единства» [Выготский, 1982, т. 2, с. 14-15].

\section{2. Действия, опосредованные артефактами}

На предпоследнем этапе «Логики», прямо перед Абсолютной идеей, когда «понятие восходит до свободного существования», Гегель разрабатывает «умозаключение действования» (der Schlusse des Handelns) - краеугольный камень теории действия, который становится ключевым звеном, связывающим все три книги «Энциклопедии», его концепцию естествознания и теорию общества - с логикой.

Вся «Логика» вплоть до этого отрывка касалась логических категорий и не затрагивала «внешнее» (если использовать гегелевскую терминологию), но с появлением умозаключения действования в Логике появляется и «внешнее». Умозаключение действования отличается от серии умозаключений из предшествующего раздела «Логики», под за- 
главием «Субъективность», будучи последним разделом Идеи, осуществляющим переход к Абсолютной Идее.

«В умозаключении, в действовании ${ }^{1}$, первая посылка - это непосредственное соотношение благой цели с той действительностью, которой эта цель овладевает и которую она во второй посылке направляет как внешнее средство против внешней действительности» [Гегель, 1970, т. 3, с. 285].

В «Малой логике» Гегель более ясно объяснял умозаключение действования (в отрывке, изобилующем выразительными курсивами):

«Целесообразная деятельность и ее средства еще направлены вовне, ибо цель также не тождественна с объектом; поэтому она и должна сначала опосредствоваться последним. Средство как объект находится в этой второй посылке в непосредственном отношении с другим крайним термином умозаключения - с объективностью как предпосылаемой, с материалом. Это отношение есть сфера служащцих цели механизма и химизма, истиной и свободным понятием которых цель является. То обстоятельство, что субъективная цель как власть, правящая этими процессами, в которых объективное стирается и снимается, сама держится вне их и вместе с тем есть то, что в них сохраняется, - есть хитрость разума.

Прибавление. Разум столь же хитер, сколь могуществен. Хитрость состоит вообще в опосредствующей деятельности, которая, позволив объектам действовать друг на друга соответственно их природе и истощать себя в этом воздействии, не вмешиваясь вместе с тем непосредственно в этот процесс, все же осуществляет лишь свою собственную цель» [Гегель, 1974, т. 1, с. 397].

Хотя не похоже, чтобы Выготский штудировал Гегеля, в работе «Сознание в обществе» ${ }^{2}$ он цитирует Маркса, в свою очередь, цитирующего данный фрагмент в «Капитале», и поэтому знает о происхождении понятия опосредствования артефактами (artifact mediation) и его глубоком значении в философии Гегеля.

Умозаключение делает очевидным и важным тезис о том, что для реализации своей цели субъекту необходимо использовать как средство другую часть той самой реальности, которую субъект намеревается изменить. Одними мыслями мир не изменишь. Может, это довод простого здравого смысла, но это важная и фундаментальная истина, касающаяся всех целенаправленных действий: мысли субъекта становятся материальной реальностью и противостоят другим субъектам как объективная материальная реальность только благодаря опосредованности действий субъекта материальными средствами, то есть с помощью посредствующих артефактов. Такими артефактами могут быть голос или рука действующего человека, инструмент или участок земли, используемые в труде; это может быть символ - например, знаки на странице или экране. Этот отрывок обычно упускается из виду во введениях в философию Гегеля, мистифицируя переход от логических категорий к понятиям естественных наук, касающимся материальных процессов, не говоря уже о процессах сочиильных.

Умозаключение действования также объясняет, как категории Логики приходят к видимому внешнему существованию, в виде форм природной и социальной жизни. В этом умозаключении материальная реальность действует на саму себя в соответствии с присущей ей природой, опосредованной человеческим субъектом, каковы бы ни были его субъективные намерения, и тем самым реализует Понятие как нечто объективное и природное, как часть материальной культуры общества, через посредство добровольного че-

${ }^{1}$ В оригинале: «В умозаключении действования (In dem Schlüsse des Handelns)». - Прим. nep.

2 «Mind in Society» - англоязычное издание работы Выготского, известной у нас под редакторским заглавием «История развития высших психических функций». Она представляет собой компиляцию как минимум двух текстов, которые в настоящее время считаются утерянными. Прим. пер. 
ловеческого действия. Именно через опосредованность действий внешними объектами и процессами субъект формирует понятие Природы.

Предметы, которые люди используют в качестве средств в своих действиях, как правило, является не дарами Природы как таковой (хотя в них всегда есть также и природное), но продуктами деятельности других людей. Как правило, это культурные продукты, нормы употребления и цели которых объективированы в самих этих артефактах; например, форма молота явно предназначена для забивания гвоздей. Соответственно, человек-субъект не только «пользуется механическими, физическими, химическими свойствами вещей для того, чтобы в соответствии со своей целью применить их как орудия воздействия на другие вещи», так, чтобы «данное самой природой стало органом его деятельности» [Маркс 1960, с. 190], но пользуется еще и всей культурой общества, частью которого он является.

На взгляд Гегеля, и субъект, и объект представляют собой не зависящие друг от друга целостности, причем средства и объект, в конечном счете, более сильны, нежели человеческие намерения:

«То, что цель непосредственно соотносится с объектом и делает его средством, равно как и то, что она через него определяет другой объект, можно рассматривать как насилие, поскольку цель представляется имеющей совершенно другую природу, чем объект, и оба объекта также суть самостоятельные по отношению друг к другу целокупности... Постольку средство выше, чем конечные цели внешней целесообразности; плуг нечто более достойное, нежели непосредственно те выгоды, которые доставляются им и служат целями» [Гегель, 1970, т. 3, с. 199-200].

Хотя личность может делать то, что выбирает сама, но наши цели, поскольку мы существа природные и культурные, в действительности даны нам, и «орудие сохраняется, между тем как непосредственные выгоды преходящи и забываются. Посредством своих орудий человек властвует над внешней природой, хотя по своим целям он скорее подчинен ей» [Гегель, 1970, т. 3, с. 200].

В этом разделе теории действия в гегелевской Логике, видно, что отдельные человеческие существа и формообразования сознания, в которых они действуют, суть просто средства, с помощью которых раскрывает себя Дух. В той мере, в какой наши действия должны иметь некий результат, мы мотивированы и вместе с тем связаны и естественной необходимостью, и возможностями, заложенными в материальной культуре, окружающей нас, и нашими собственными действиями, и действиями предшествующих поколений. Абсолютная необходимость внешних средств в опосредствовании человеческих замыслов лежит в основе этого утверждения.

Молодой Гегель предвосхитил категорию артефакта, когда определил инструмент как «норму труда», речь - как «инструмент разума», а ребенка - как «абсолютный опосредствующий термин» (absolute mediating term). Все эти разновидности артефактов являются внешними материальными объектами или процессами $u$ в то же время формируются и используются в человеческой деятельности. Только мысль, соответствующая таким материальным объектам и процессам и манифестируемая через их средства и объекты, активна в мире и является частью Geist (нем. Духа).

Однако не любой, первый встречный материальный объект или процесс функционирует таким образом в манифестации Духа. Например, местный климат здесь, в Мельбурне, делает разговоры о погоде между жителями нашего города взаимно понятными. Но когда мы говорим друг с другом о погоде, тот факт, что все мы имеем опыт относительно одного и того же объекта, ни необходим, ни достаточен для взаимопонимания, поскольку все мы переживаем эту погоду по-разному. Если я говорю вам о погоде, погода не участвует в этом действии; только произнесенные слова опосредствуют мое действие в отно- 
шении к вам. Если я говорю по-английски, то будут понятны только те значения, которые вы понимаете по-английски; если же вы не понимаете этот язык, то общение совсем не получится. Другая проблема - роль общих материальных условий. Понятия о погоде реализуются только через общение и деятельность, связанную с погодой. Если же погода является не более чем фоном деятельности, понятие о погоде не может существовать.

Согласно умозаключению действования, между субъектом и объектом существуют две связи: одна - непосредственная, например, переживание погоды, а другая - опосредствованная, например, слова и формы выражения, с помощью которых мы научились реагировать на погоду. Посредствующий элемент не исключает непосредственного контакта с объектом, действуя как буфер между субъектом и объектом, но вместе с тем и «управляя» этим контактом.

Важное значение в данном плане имеют Слова Гегеля в начале «Науки логики», в очерке «С чего должна начинаться наука?»: «Нет ничего ни на небе, ни в природе, ни в духе, ни где бы то ни было, что не содержало бы в такой же мере непосредственность, в какой и опосредствование» [Гегель 1970, т. 1, с. 124].

\section{Выготский об опосредствовании артефактами}

Несмотря на то, что к 1980-м годам среди исследователей творчества Выготского утвердилось мнение, что в большинстве его работ «действия, опосредованные артефактами», рассматриваются как единица анализа, с 1930 года Выготский старательно дистанцировался от использования категории «артефакт» в подобном ключе, смешивая (lumping) использование орудий труда с использованием символов в коммуникативном акте. Объединение этих двух видов опосредствования заключало в себе, по мнению Выготского, риск редукици символических действий, таких как речь и письмо, к труду - эта тенденция обнаружила себя в позднейших работах некоторых его коллег [Леонтьев 1998]. Выготский использовал также и другие единицы анализа, помимо действий, опосредованных артефактами, как отмечалось в другой моей работе [Blunden 2017].

\section{3. Различие между действиями и деятельностью}

Гегель излагает свою теорию деятельности в разделе о нравственности в «Философии права». Противоречие между целью (Vorsatz) и намерением (Absicht) действия и противоречие между намерением и благом (Wohl) являются ключевыми понятиями его анализа. Эти понятия не просто отличаются или находятся на разных уровнях абстракции, но противоречат друг другу, и основанием для этих противоречий является рациональное человеческое действие. Описываемая Гегелем структура действия не просто моральная, когнитивная или аффективная структура, принадлежащая конкретному деятелю, а скорее концептуальная и этическая структура общества в целом.

Гегель показывает, что намерение, реализованное действием, существенно отличается от цели действия. В свою очередь, цель существенно отличается от блага, которое субъект преследует в своем намерении. Противоречие между целью и намерением, как показал А.Н. Леонтьев [1975], является определяющим фактором «действия» ${ }^{1}$, как основной единицы деятельности, а различие между намерением и благом - определяющий фактор «деятельности», молярной единицы, структурирующей разделение труда и социальную борьбу.

Гегель развил эти идеи в форме нравственной философии, но в ней имплицитно содержится теория действия, раскрывающая структуру общества.

\footnotetext{
${ }^{1}$ А.Н. Леонтьев проводит различие между намеренным «действием» и «операцией», осу-
} ществляемой автоматически. - Прим. пер. 


\section{4. Различие между псевдопонятием и истинным понятием}

Во времена Гегеля большинство логиков считали, что понятие равносильно перечню существенных атрибутов, и то же самое мнение бытует по сей день. Предмет гегелевской «Логики» - понятия, их генезис и развитие, и Гегель произвел революцию в понимании «понятия» (Begriff). Вплоть до 1931 года Выготский толковал «понятия» в конвенционалистском духе формальной логики, и эта концепция нашла свое отражение в работе Лурии в Центральной Азии в 1931 году ${ }^{1}$. Возможно, в результате совместной работы с последователями советского философа Деборина Выготский изменил свой взгляд [на природу понятия], что сказалось на всех его работах, вышедших после 1931 года.

Гегель проводил следующее различие между «понятием» и абстрактно-общим в формальном, метафизическом мышлении:

«Когда говорят о понятии, то обычно перед нашим умственным взором возникает лишь абстрактная всеобщность, и обычно поэтому понятие определяют как общее представление. Говорят, согласно этому, о понятии цвета, растения, животного и т.д. и считают, что эти понятия возникли благодаря тому, что опускается все особенное, отличающее друг от друга различные цвета, растения, животные и т.д., и сохраняется то, что у них есть общего. Таков рассудочный способ понимания понятия, и чувство здесь право, объявляя такие понятия пустыми и бессодержательными, голыми схемами и тенями.

Но всеобщее понятие не есть только общее, которому противостоит особенное, обладающее своим собственным существованием; оно есть, напротив, само себя обособляющее (специфицирующее) и с незамутненной ясностью остающееся у самого себя в своем другом. В высшей степени важно как для познания, так и для практического поведения, чтобы мы не смешивали голое общее с истинно всеобщим, с универсальным» [Гегель 1974 , т. 1, c. 345-346].

Выяснение того, как Гегель трактовал «понятие», увело бы нас далеко от сказанного выше в связи с концепцией «единицы анализа».

«Абстрактную всеобщность», о которой говорил Гегель, Выготский справедливо назвал «псевдопонятием» - формой абстрактного обобщения, соединяющей объекты при помощи общих черт, им присущих; это напоминает понятийное мышление, потому что в ограниченной области опыта такие псевдопонятия охватывают те же объекты и ситуации и обозначаются теми же самыми словами, что и истинное понятие.

«Псевдопонятия составляют не только исключительное достояние ребенка. В псевдопонятиях чрезвычайно часто происходит и мышление в нашей обыденной жизни. С точки зрения диалектической логики понятия, встречающиеся в нашей житейской речи, не являются понятиями в собственном смысле. Они являются, скорее, общими представлениями о вещах. Однако не подлежит никакому сомнению, что они представляют собой переходную ступень от комплексов и псевдопонятий к истинным понятиям» [Выготский, 1982 , т. 2, с. 168$]$.

Примечательно, что эти два автора [Выготский и Гегель] различали абстрактные обобщения и истинные понятия одинаковым образом, один - с точки зрения психологии развития, другой - с точки зрения логики.

\section{Заключение}

Четыре указанных выше концептуальных идеи не исчерпывают пути, на которых Выготский, Леонтьев и их последователи продолжили работу, начатую Гегелем. В частности, можно было бы упомянуть следующее:

${ }^{1}$ В 1931-1932 годах А.Р. Лурия предпринял две экспедиции в Узбекистан для проверки гипотезы о культурных различиях между структурами человеческого восприятия. - Прим. пер. 
1. Выготский, подобно объективному идеалисту Гегелю, рассматривает понятия как имплицитно заложенные в констелляциях материальной культуры способы ее использования в обществе, а не как субъективные образования, создаваемые индивидуальным мозгом.

2. Концепция генезиса речи и мышления у Выготского:

«До известного момента то и другое [речевое и интеллектуальное] развитие идет по различным линиям, независимо одно от другого. В известном пункте обе линии пересекаются, после чего мышление становится речевым, а речь - интеллектуальной» [Выготский, 1982, т. 2, с. 105].

Гегель представлял генезис современного государства подобным же образом: различные ветви власти - законодательная, исполнительная, монарх - исторически имеют разное происхождение, но собираются воедино как элементы одного организма. В зрелом состоянии ни один из них не может существовать без всего организма, но каждый орган работает независимо в соответствии со своими полномочиями, аналогично тому, как взрослые люди могут размышлять о чем-либо, не произнося этого вслух, и говорить нечто, в то же время думая о чем-то другом.

3. Несмотря на то, что Выготский сформулировал несколько положений о свободе воли, свидетельствующих о недостаточной философской грамотности, он превосходно решил проблему свободной воли в своей теории развития ребенка [Выготский, 1982, т. 4, с. 243-385], показав, как естественная воля новорожденного трансформируется в своем развитии через ряд фаз, в которых ребенок становится физически, биологически, психологически и, наконец, социально автономным, в конечном счете обретая свободную волю взрослого гражданина, свободно действуя с осознанием своего социального положения и исторического контекста.

Таким же образом во Введении к «Философии права» продвигалась и мысль Гегеля. Человек выходит из животного царства с естественной волей, которая оставляет его в плену собственных желаний при наличии средств их удовлетворения и терпимого отношения к ближнему. Однако на завершающих стадиях филогенеза, с овладением языком, а затем и последующим историческим становлением государств, способных гарантировать права, обеспечивать развитие человека как нравственного субъекта и его участие в суверенном государстве, человек развивает (develops) свободную волю. Выготский и Гегель разделяли такой развивающий подход (developmental approach) к проблеме, вместо того, чтобы метафизически противопоставлять свободную волю естественной, запутываясь в возникающих противоречиях.

Синергия обширна, так как подход Выготского - развивающий, а не основанный на неизменных категориях, и этот подход к реальности был инициирован Гегелем.

Стоит отметить, что четыре концептуальных идеи, выделенные в данной статье, редко становятся предметом внимания гегелеведов, хотя и хорошо известны исследователям творчества Выготского и, как мы видели, открыто предвосхищались Гегелем. Учитывая, что Выготский, по всей вероятности, никогда не изучал Гегеля [см.: Blunden 2009], это достижение выдающееся.

\section{Список литературы}

1. Выготский Л.С. 1982. Собрание сочинений: в 6 т. М.: Педагогика.

2. Гегель Г.В.Ф. 1970. Наука логики: в 3 т. М.: Мысль.

3. Гегель Г.В.Ф. 1974. Энциклопедия философских наук: в 3 т. М.: Мысль.

4. Гегель Г.В.Ф. 1990. Философия права. М.: Мысль. 524 с.

5. Леонтьев А.Н. 1975. Деятельность. Сознание. Личность. М.: Политиздат. 304 с.

6. Леонтьев А.Н. 1998. Учение о среде в педологических работах Л.С. Выготского. Вопросы психологии, 1: 108-124.

7. Маркс К. 1960. Капитал. Т. 1. Маркс К., Энгельс Ф. Сочинения: в 50 т. М.: Политиздат. T. 23. $907 \mathrm{c}$. 
8. Маркс К. 1961. Замечания на книгу А. Вагнера «Учебник политической экономии». Маркс К., Энгельс Ф. Сочинения: в 50 т. М.: Политиздат. Т. 19. С. 369-399.

9. Blunden A. 2009. From where did Vygotsky get his Hegelianism? URL: https://www.ethicalpolitics.org/ablunden/pdfs/Vygotskys-Hegelianism.pdf (дата обращения 01.06.2020).

10. Blunden A. 2017. The Germ Cell of Vygotsky's Science, in: Vygotsky and Marx, ed. by C. Ratner \& D. N.H. Silva. Routledge. 207 p.

11. Hegel G.W.F. 1979. System of ethical life (1802/3) and First Philosophy of Spirit (1803/4). New York: State University of New York Press. 288 p.

\section{References}

1. Vygotsky L.S. 1982. Sobranie sochinenij [Works]. In 6 vol. Moscow, Pedagogika.

2. Hegel G.W.F. 1970. Nauka logiki [Science of Logic]. In 3 vol. Moscow, Mysl’.

3. Hegel G.W.F. 1974. Ehnciklopedija filosofskikh nauk [Encyclopaedia of the Philosophical Sciences]: In 3 vol. Moscow, Mysl'.

4. Hegel G.W.F. 1990. Filosofija prava [Philosophy of Right]. Moscow, Mysl'. 524 p.

5. Leontiev A.N. 1975. Dejatel'nost'. Soznanie. Lichnost' [Activity. Consciousness. Personality]. Moscow, Politizdat. 304 p.

6. Leontiev A.N. 1998. Uchenie o srede v pedologicheskikh rabotakh L.S. Vygotskogo [Study of the environment in the pedological works of L.S. Vygotsky]. Voprosy psikhologii, 1: 108-124.

7. Marx K. 1960. Kapital. Vol. 1. Marx K., Engels F. Sochinenija [Works]. In 50 vol. Moscow: Politizdat. $907 \mathrm{p}$.

8. Marx K. 1961. Zamechanija na knigu A. Wagnera «Uchebnik politicheskoj ehkonomii» [Notes on Adolph Wagner's Textbook of Political Economy]. Marx K., Engels F. Sochinenija [Works]. In 50 vol. Moscow, Politizdat. Vol. 19: 369-399.

9. Blunden A. 2009. From where did Vygotsky get his Hegelianism? URL: https://www.ethicalpolitics.org/ablunden/pdfs/Vygotskys-Hegelianism.pdf (date of request 01.06.2020).

10. Blunden A. 2017. The Germ Cell of Vygotsky’s Science, in: Vygotsky and Marx, ed. by C. Ratner \& D. N.H. Silva. Routledge. 207 p.

11. Hegel G.W.F. 1979. System of ethical life (1802/3) and First Philosophy of Spirit (1803/4). New York: State University of New York Press. 288 p.

\section{ИНФОРМАЦИЯ ОБ АВТОРЕ}

Бланден Энди, секретарь Марксистского сетевого архива (marxists.org), автор монографий по философии Гегеля и теории деятельности, Мельбурн, Австралия

\section{ИНФОРМАЦИЯ О ПЕРЕВОДЧИКЕ}

Майданский Андрей Дмитриевич, доктор философских наук, профессор кафедры философии и теологии Белгородского государственного национального исследовательского университета, Белгород, Россия

\section{INFORMATION ABOUT THE AUTHOR}

Blunden Andy, Secretary of the Marxist network archive (marxists.org), author of monographs on Hegel's philosophy and theory of action, Melbourne, Australia

\section{INFORMATION ABOUT THE TRANSLATOR}

Andrey D. Maidansky, Doctor of Philosophy, Professor of the Department of philosophy and theology Belgorod State National Research University, Belgorod, Russia 